\title{
Unknown pleasures
}

\author{
Ben Bramble ${ }^{1}$
}

Published online: 26 February 2019

(C) The Author(s) 2019

\begin{abstract}
According to attitudinal theories of (sensory) pleasure and pain, what makes a given sensation count as a pleasure or a pain is just the attitudes of the experiencing agent toward it. In a previous article, I objected to such theories on the grounds that they cannot account for pleasures and pains whose subjects are entirely unaware of them at the time of experience. Recently, Chris Heathwood and Fred Feldman, the two leading contemporary defenders of attitudinal theories, have responded to this objection, in very different ways. In this paper, I reconstruct and evaluate these responses. My conclusion is that neither response succeeds.
\end{abstract}

Keywords Pleasure · Pain · Attitudinal theories · Introspective failure · Desire · Subjectivism $\cdot$ Value $\cdot$ Well-being $\cdot$ Reasons for action

\section{Introduction}

According to attitudinal theories of (sensory) pleasure and pain, what makes a given sensation count as a pleasure or a pain is just the attitudes of the experiencing agent toward it. On the most plausible existing such theory, Chris Heathwood's,

a sensation $\mathrm{S}$, occurring at time $\mathrm{t}$, is a sensory pleasure at $\mathrm{t}$ iff the subject of $\mathrm{S}$ desires, intrinsically and $d e r e$, at $\mathrm{t}$, of $\mathrm{S}$, that it be occurring at $\mathrm{t}$...[and] a sensation $\mathrm{S}$, occurring at time $\mathrm{t}$, is unpleasant at $\mathrm{t}$ iff the subject of $\mathrm{S}$ desires, intrinsically and de re, at $\mathrm{t}$, of $\mathrm{S}$, that it not be occurring at $\mathrm{t}^{1}$

\footnotetext{
${ }^{1}$ Heathwood (2007, p. 32).

Ben Bramble

b.e.bramble@gmail.com

1 University of Liverpool, Liverpool, UK
} 
In a previous article, I objected to such theories on the grounds that they cannot account for pleasures and pains whose subjects are entirely unaware of them at the time of experience. ${ }^{2}$ One cannot want de re that a feeling be occurring if one has no idea that it is occurring. What evidence is there for the possibility of pleasures and pains whose subjects are entirely unaware of them? I appealed to a range of cases, two of which have received quite a bit of attention in subsequent literature. The first is Daniel Haybron's case of the whining refrigerator. Haybron writes:

Perhaps you have lived with a refrigerator that often whined due to a bad bearing. If so, you might have found that, with time, you entirely ceased to notice the racket. But occasionally, when the compressor stopped, you did notice the sudden, glorious silence. You might also have noted, first, a painful headache, and second, that you'd had no idea how obnoxious the noise wasor that it was occurring at all-until it ceased. But obnoxious it was, and all the while it had been, unbeknownst to you, fouling your experience as you went about your business. In short, you'd been having an unpleasant experience without knowing it. ${ }^{3}$

The second case is Oliver Sacks's patient, who, after losing his sense of smell, remarks:

it was like being struck blind. Life lost a good deal of its savour-one doesn't realise how much 'savour' is smell. You smell people, you smell books, you smell the city, you smell the spring-maybe not consciously, but as a rich unconscious background to everything else. My whole world was suddenly radically poorer. ${ }^{4}$

Recently, Chris Heathwood and Fred Feldman, the two leading contemporary defenders of attitudinal theories, have responded to this objection, in very different ways. Heathwood accepts that there are pains and pleasures going on in the Haybron and Sacks cases, but rejects my claim that the subjects in these cases are entirely unaware of them. He thinks there is some awareness of them here. Feldman, for his part, rejects my claim that there are pains and pleasures going on in these cases at all.

In this paper, I will reconstruct and evaluate Heathwood's and Feldman's responses. My conclusion will be that neither response succeeds.

\section{Heathwood's response}

Heathwood accepts that the subjects in the Haybron and Sacks cases are experiencing pleasures and pains they are in a sense unaware of. What sense is this? Heathwood writes:

\footnotetext{
2 Bramble (2013).

3 Haybron (2008, p. 205).

${ }^{4}$ Quoted in Rachels (2004, p. 225).
} 
they do not, before the sensation stops, occurrently believe that they are experiencing the sensation, at least not confidently, and nor would they come to believe it even if they were to attend to the question. ${ }^{5}$

They lack, as Heathwood terms it, strong awareness of these sensations.

However, Heathwood goes on, there is a different sense in which these subjects are aware of the sensations in question. This must be so, he says, since

1. these subjects notice the cessation of these sensations, and

2. one cannot notice the cessation of a sensation without having been in some sense aware of it beforehand.

The kind of awareness of their sensations that these subjects possess Heathwood terms weak awareness. ${ }^{6}$

Heathwood does not argue for (1). But he does argue for (2), in the following way:

To notice [the] cessation [of a sensation] is to notice a change in some aspect of one's experience, and one can notice a change in some aspect of one's experience only if one had some kind of awareness of how one's experience was with respect to that aspect before the change and also an awareness of how it was with respect to that aspect after the change.

Heathwood concludes by considering whether one's having weak awareness of a sensation is sufficient to allow one to form a de re attitude toward the sensation. He notes that I have "given us no reason to think that it can't", 8 and then offers a positive reason for thinking that it can:

Consider Haybron's case. The refrigerator is whining loudly. Deep in your work, you don't notice it. Then the compressor stops, and you do notice the sudden, glorious silence. You also realize this: that 'all the while it had been,

\footnotetext{
5 Heathwood (2017, p. 6).

${ }^{6}$ Feldman interprets Heathwood as offering an account of what weak awareness of a sensation consists in-i.e., that it consists in a disposition to notice the cessation of the sensation. Feldman objects to such an account, on what seem to me solid grounds. But Heathwood does not seem to me well interpreted as offering such an account. He seems better interpreted as saying merely that there is some sense in which the subjects in the Haybron and Sacks cases are aware of their sensations, without committing himself to any particular account of what this sense is. This is for three reasons. First, charity. The account Feldman attributes to Heathwood of what weak awareness consists in is, for reasons Feldman nicely explains, very implausible. It is hard to believe that Heathwood would be tempted by, or accept, such an account. Second, Heathwood's argument here does not require an account of what weak awareness consists in-it would be enough to show that there must be some kind of awareness, whatever it consists in. Third, while Heathwood does sometimes speak as if he is offering an account of what weak awareness consists in, at other times he explicitly denies this. For example, he writes: "That the subject would notice it if the sensation were to stop shows that the sensation is a part of the subject's awareness (in some sense of awareness). But it is evidently not constitutive of this sort of awareness" (Heathwood (2017, p. 6). Note the italicized text (my emphasis). While Heathwood uses the word "shows" here, the italicized text suggests that "shows" here means just "provides evidence".

7 Heathwood (2017, p. 5).

${ }^{8}$ Heathwood (2017, p. 9).
} 
unbeknownst to you, fouling your experience as you went about your business'. Now consider this question: All the while, had the noise been, unbeknownst to you, bothering you? Surely the answer is 'Yes'. Surely if it is true that a sensation was 'fouling your experience', then it follows that the sensation was bothering you. It sounds contradictory to say, 'this smell is fouling my experience, though it's not bothering me at all'. But bother consists in having an attitude. To be bothered by something is to mind it or to be annoyed by it or disturbed by it. If someone is bothered by the fact that it is raining, that person has an attitude towards the fact that it is raining. Likewise, if they are bothered by the refrigerator's whining, they have an attitude towards that. Thus, not only is there no reason to deny that the subject in Haybron's case could have been having a negative attitude towards the whining sound, it seems clear that they were having such an attitude. ${ }^{9}$

So ends Heathwood's response.

\section{Evaluating Heathwood's response}

There are, I think, five problems with Heathwood's response. To begin with, it is not clear that what the subjects in the Haybron and Sacks cases notice is the cessation of a sensation at all. Neither Haybron nor Sacks, at least, speak in these terms. What Haybron says one notices in the refrigerator case is "a glorious silence". This sounds more like a pleasurable sense of relief, happening only after a pain has ended, rather than a pain itself ending. Haybron seems to be thinking of the refrigerator case as one in which the subject experiences a pleasure-not a pain going away or ending - and then infers from this pleasure the existence of some past pain that has now ended.

What of Sacks's patient? Sacks, also, does not say that his patient notices his olfactory pleasures ending or going away. Instead, according to Sacks, what his patient notices seems to be the aftermath of these pleasures, something happening in his experiences (or some feature of them) after these pleasures have ended-say, a feeling of emptiness or experiential poverty, a sort of 'felt absence'. Again, the patient seems best construed as inferring past olfactory pleasures from the empty way that he is feeling now. At least, Heathwood has said nothing to cast doubt on this plausible interpretation.

The second problem with Heathwood's response is that even if it is true that Haybron's subject notices his pain ending, and Sacks's patient notices his pleasures ending, it does not seem necessary that they were in any sense aware of these sensations before they noticed them ending, let alone for their entire duration. Perhaps the very first time these subjects were ever aware of these sensations was when they started to end. Indeed, it might have been just because these sensations started to end that their attention was first drawn to them. There are many cases, after all, where one's first awareness of some sensation is of its ending. For example,

9 Heathwood (2017, p. 9). 
one might walk into a café and notice (much to one's disappointment) one's favourite song on the café's radio fading out.

The third problem with Heathwood's response is that even if it is true that the subjects in the Haybron and Sacks cases must have been in some sense aware of their painful and pleasurable sensations beforehand - and, moreover, for their entire durations - these two cases form only part of my evidence for the possibility of pleasures and pains of which we are entirely unaware. Heathwood's response to these cases has no application to this other evidence. What is this other evidence? There is, for example, Haybron's observation that

stressed or anxious individuals may discover their emotional state only by attending to the physical symptoms of their distress. Presumably being tense, anxious, or stressed detracts substantially from the quality of one's experience, even when one is unaware of these states. ${ }^{10}$

In such cases, we seem to acquire evidence that we are experiencing pleasures or pains, not by noticing these sensations or their cessation, but just by noticing certain physical symptoms or manifestations of them (or having these physical symptoms or manifestations drawn to our attention by others, sometimes medical professionals). That one's heart is beating faster than it should be, one has goose pimples on one's arm, one's face is growing redder, etc., might alone be evidence of certain phenomenology in one, including pleasures and pains (whether one is in a position to introspect this phenomenology or not).

Consider, also, Eric Schwitzgebel's case of the husband who is entirely oblivious to his own (unpleasant) feelings of anger while doing the washing up:

My wife mentions that I seem to be angry about being stuck with the dishes again...I deny it. I reflect; I sincerely attempt to discover whether I'm angryI don't just reflexively defend myself but try to be the good self-psychologist my wife would like me to be-and still I don't see it. I don't think I'm angry. But I'm wrong, of course, as I usually am in such situations: My wife reads my face better than I introspect. Maybe I'm not quite boiling inside, but there's plenty of angry phenomenology to be discovered if I knew better how to look. Or do you think that every time we're wrong about our emotions, those emotions must be nonconscious, dispositional, not genuinely felt? Or felt and perfectly apprehended phenomenologically but somehow nonetheless mislabeled? Can't I also err more directly? ${ }^{11}$

My point is not, of course, that this proves that there can be painful or unpleasant feelings of which one is entirely unaware. But it seems to constitute some important evidence in favour of this view. And Heathwood does not address it.

There are many other kinds of cases, too, that seem to provide some evidence of the possibility of pleasures and pains whose subjects are entirely unaware of them at the time of experience. Suppose I very lightly brush your arm with my finger. Did

\footnotetext{
${ }^{10}$ Haybron (2008, p. 222).

11 Schwitzgebel (2008, p. 252).
} 
you feel a faint pleasure here, nothing at all, or else some hedonically neutral feeling? It might be hard to tell. You might try to introspect the answer, and give up. Here, it is natural to think, you might have been feeling some pleasure without having any awareness of it.

The fourth problem with Heathwood's response is with his positive argument for the claim that weak awareness of a sensation is sufficient for one to form a de re attitude toward it. This argument can be reconstructed as follows:

1. If a sensation is "fouling your experience", then it must be "bothering you".

2. If a sensation is "bothering you", then you must have some attitude toward it.

3. The noise of the refrigerator was fouling the experience of Haybron's subject.

\section{Therefore,}

4. Haybron's subject had some attitude toward the noise of the refrigerator.

(2) and (3) are certainly plausible. But I see no reason to accept (1). For a sensation to "foul" one's experience seems just for it to be painful or unpleasurable. It doesn't follow that it is bothering one. Heathwood needs to provide some argument for (1). Saying merely "It sounds contradictory to say, 'this smell is fouling my experience, though it's not bothering me at all'" is inadequate.

The fifth problem with Heathwood's response is that invocations of weak awareness-whatever weak awareness consists in-seem insufficient to address an expanded version of the objection I gave in a later article. ${ }^{12}$ In this article, I wrote:

It may be objected that the relevant sort of awareness...might take place unconsciously. While Sacks' patient, for example, was not consciously aware of his olfactory pleasures, he was aware of them at some level. But... it is not just olfactory pleasures that can fly beneath our cognitive radar. At any given time, there are likely hundreds or even thousands of respects in which our experiences are subtly pleasurable. We are getting pleasures from the visual perception of colours, light, depth, the size of things, the shape of things, symmetries and asymmetries in our environment, and so on and so forth. We are getting pleasures also from sounds - the tone of one's loved one's voice, the rattle of the trolley car, the rustle of leaves in a nearby tree, the background chatter of people in the bar, the ceasing of the hum of the air conditioner, and so on. Then there are pleasures of having a healthy body in all sorts of waysof feeling invigorated without realising it, or having a clear head. There are pleasures of feeling a light breeze on one's cheek, or a patch of warmth from the sun on one's arm as the clouds briefly separate. There are pleasures associated with our unconscious beliefs about the good health of our loved ones, or our continuing success toward our goals, or the coming end to the semester. There are, in addition, many unconscious unpleasurable experiences-subtle aches and pains, vague annoyances, background anxieties, anger or melancholy arising from memories of childhood trauma long

12 Bramble (2015). 
repressed or even from the awareness that we are all going to die someday. At any given time, all these pleasures and pains (and more!) may be going on in one unconsciously. ${ }^{13}$

What is the problem here? It is, as I put it then:

It is highly implausible that we understand the jumble of ways we are feeling at any given time well enough on any level to have the sort of fine-grained awareness of it all that is necessary on a theory like Heathwood's to allow us the sort of attitudes that ground pleasurableness. ${ }^{14}$

There is so much going on hedonically in our experiences at any one time, it is implausible that we could be aware of it all-let alone that we are always, necessarily, aware of it all-even weakly or unconsciously. But this is just what attitudinal theories require, for if we were not aware of it all, these sensations would not be so much as available for us to form the sort of de re attitudes toward them that, on these theories, make them count as pleasures and pains. For this reason, attitudinal theories require that we possess unbelievably vast unconscious cognitive processing powers. They must, as I put it then, "attribute far more than is plausible to the unconscious mind". 15,16

I want to finish this section by mentioning a possible way around my expanded version of the objection. This is to switch to what we might call an idealised attitudinal theory. On such a theory, a sensation counts as a pleasure, not in virtue of one's actually wanting it, but in virtue of its being the case that one would want it if one were aware of it. This would allow an attitudinal theorist to explain not only why there are pains and pleasures going on in the Haybron and Sacks cases despite the subjects being entirely unaware of them, but also the immense volume and

\footnotetext{
13 Bramble (2015, p. 201).

14 Bramble (2015, p. 201).

15 Bramble (2015, p. 201).
}

16 A parallel problem exists for higher-order thought (HOT) theories of consciousness. On HOT theories, a sensation gets to count as conscious just in virtue of one's being aware of it. But some philosophers have pointed out that there seem to be many conscious experiences that are far too complex for us to be aware of all that is going on in them. Carruthers (2016) nicely articulates this criticism in the following: "Consider just how rich and detailed a conscious experience can be. It would seem that there can be an immense amount of which we can be consciously aware at any one time. Imagine looking down on a city from a window high up in a tower-block, for example. In such a case you can have phenomenally conscious percepts of a complex distribution of trees, roads, and buildings; colors on the ground and in the sky above; moving cars and pedestrians; and so on. And you can-it seems-be conscious of all of this simultaneously. According to actualist higher-order thought theory, then, you would need to have a distinct activated higher-order belief for each distinct aspect of your experience-either that, or just a few such beliefs with immensely complex contents. Either way, the objection is the same. For it seems implausible that all of this higher-order activity should be taking place (albeit non-consciously) every time someone is the subject of a complex conscious experience...[Think] of the amount of cognitivel neural space that these beliefs would take up!... [Similarly,] think of immersing yourself in the colors and textures of a Van Gogh painting, for example, or the scene as you look out at your garden-it would seem that one can be phenomenally conscious of a highly complex set of properties, which one could not even begin to describe or conceptualize in any detail". 
complexity of pleasures and pains that we experience in the background, even in single moments.

But there is a serious problem for any such idealised attitudinal theory of pleasure. This is that it seems there might be pleasures whose phenomenal nature one cannot introspect clearly. Consider, for example, pleasures of being 'zoned or spaced out' (say, after taking certain kinds of drugs, or as a result of being a very basic or simple-minded sort of creature). These might be intrinsically hazy. One might be unable to understand well what these pleasures are like, since any attempt to behold them clearly would necessarily change or destroy them (or change or destroy oneself). They might, it seems, be logically inaccessible to us-necessarily beyond our cognitive reach.

I conclude that Heathwood's response fails.

\section{Feldman's response}

While Heathwood accepts that the subjects in the Haybron and Sacks cases are experiencing pains and pleasures, Feldman denies this. He addresses the two cases in turn, starting with Haybron's. He reconstructs my argument as follows:

Bramble claims that since the subject notices the cessation of the unpleasant noise, he must have been experiencing it previously, even when he was not conscious of it. ${ }^{17}$

He objects to this argument in the following way:

There is something funny about saying that a subject could first begin to notice a certain sensation only at the moment when it ceases. Suppose a person is 'experiencing' a pleasure of which she is entirely unaware during some period of time. Suppose that at a certain instant the unconscious pleasure suddenly ceases. Now the person is no longer experiencing that pleasure-the one of which she was not conscious during the time it was happening. Assume, to make the case simpler, that as far as possible the person's experience is otherwise not affected. It strikes me that it will be impossible for the person to notice any change in her experience at the moment of cessation. It's hard to imagine how things could seem any different to her after the cessation. After all, she was 'entirely unaware' of the pleasure beforehand, and she was entirely unaware of it afterwards. Everything else remains the same. How could the cessation of the pleasure make any difference ${ }^{18}$

Where Heathwood's response was, in short, 'Since you notice the cessation of the sensation, you must have been aware of it beforehand', Feldman's response is 'If you'd been having a sensation earlier without being in any way aware of it, then you wouldn't be able to notice its cessation'.

17 Feldman (2018, p. 4). 
So, what is going on in the Haybron case, according to Feldman? He says that reflection on one's phenomenology in such cases reveals "three phases":

(1) "a period of time during which the refrigerator is whining but I am not aware of it...there are various sound-related vibrations going on in my ears and perhaps some electrical goings-on in my auditory nerves... [but] the sound is not part of my conscious experience."

(2) "a transitional phase during which the compressor is shutting down. As the compressor slows down, the noise it makes changes. The change in sound catches my attention. Thus, the sound of the refrigerator comes into consciousness...During this phase I am aware of the fading sounds. Now we can describe the sounds as painful (or at least unpleasant) since I take intrinsic attitudinal displeasure in those sounds."

(3) "the sound of the refrigerator has ceased. The vibrations in the auditory system have ceased as well."19

In none of these phases, Feldman notes, is one having a pain one is entirely unaware of.

Next, Feldman considers the Sacks case. He writes:

I am uneasy about the idea that these unconscious aromatic experiences are really pleasures. Imagine a life filled with unconscious aromatic experiences. Imagine further that aside from these experiences the subject never has any pleasures or pains. Surely the subject would not be impressed if a hedonist were to tell him that he has had lots of pleasant sensations and thus that he has enjoyed a life of high personal welfare. If he was never aware of any of these aromatic experiences, they seem not to be the sort of thing that a sensory hedonist has in mind when he says that pleasant sensations are welfare enhancing. ${ }^{20}$

Feldman's idea here seems to be:

1. Pleasures are welfare enhancing (i.e., non-instrumentally good for us).

2. Sensations one is entirely unaware of cannot be welfare enhancing in this way.

\section{Therefore,}

3. There can be no (sensory) pleasures one is entirely unaware of.

So, Sacks's unawareness of any prior olfactory sensations entails that, even if he'd been feeling some, they couldn't have been good for him, and so couldn't have counted as pleasures.

\footnotetext{
19 Feldman (2018, p. 7).

${ }^{20}$ Feldman (2018, p. 8).
} 


\section{Evaluating Feldman's response}

There are a number of problems with Feldman's response. The first is with his claim that if you'd been having a sensation while being entirely unaware of it, then you wouldn't be able to notice its cessation. The problem here is that it seems, as I mentioned earlier in my evaluation of Heathwood's response, that it might be precisely a sensation's starting to change or fade away that triggers one's attention to it. Oddly, Feldman himself elsewhere in his piece seems to acknowledge this possibility. In his description of what takes place during the "second phase", he writes: "The change in sound catches my attention. Thus, the sound of the refrigerator comes into consciousness". ${ }^{21}$

The second problem with Feldman's response is that, like Heathwood's, it relies on a mischaracterisation of my objection. My claim is not that what the subject notices in the Haybron case is the cessation of some sensation. What he notices is $a$ pleasurable sense of relief, from which he infers the existence of some past pain.

It might be suggested that Feldman's response applies even if what the subject notices in such a case is not the cessation of a sensation, but a pleasurable sense of relief. On this suggestion, Feldman's response would look more like this: Why think that there was some pain preceding the pleasure that Haybron's subject is aware of? Mightn't it be that the very first thing he experiences is simply this pleasure (i.e., that even if "phase two" involves a pleasure, not a pain, "phase one" involves no pain)?

However, the answer to this challenge should be obvious: there is a reliable connection in nature between pleasurable senses of relief and past pains ending. It would be odd to be feeling a pleasurable sense of relief without having had some pain recently end. For this reason, the burden seems to be on someone like Feldman to provide some good reason to think that in this kind of case one's pleasurable sense of relief is not caused by, or connected with, a past pain's ending. What else might explain it?

It is worth noting another odd thing about Feldman's response. In my original article, I cited cases like Haybron's as evidence that there are pleasures and pains we can be unaware of or even unable to introspect. Feldman's response here seems ultimately to be that we can tell that there are no such pleasures or pains through careful introspection. It would have been helpful if Feldman had offered some reason to think that we can trust our introspective faculties in these kind of cases.

Let us turn now to Feldman's discussion of the Sacks case. It is worth noting that it is somewhat strange that Feldman should have a problem with the idea of some pleasures not being good for one. In his fabulous book Pleasure and the Good Life, Feldman argues that how good a given pleasure is for one might depend on what he calls the altitude of its object-i.e., its object's "suitability to serve as an object of pleasure". ${ }^{22}$ He writes:

\footnotetext{
${ }^{21}$ Feldman (2018, p. 7).

22 Feldman (2004, p. 73).
} 
The fact that some painting is beautiful, the fact that some line of research is enlightening, the fact that some argument is valid, the fact that some pattern of behavior is morally admirable_all of these are excellent objects for someone to be pleased about. On the other hand, the fact that my body feels like this (experienced while mud-wrestling), the fact that I am feeling such-and-such tingles in my private parts, etc.,- - all of these are less well suited to be objects of attitudinal pleasure. ${ }^{23}$

He then suggests that some objects of pleasure might have altitudes of zero. Given this, he says, "a life could be full of pleasure, yet worthless". ${ }^{24}$

But now, if pleasure taken in the ugly, the false, or the bestial can fail to be good for one, why not pleasure of which one is entirely unaware? Feldman owes us some principled account of the difference here.

The right response, however, to Feldman's discussion of the Sacks case is, I believe, to reject his claim that sensations one is entirely unaware of cannot be welfare enhancing. If one is genuinely feeling a given pleasure-if it is truly a part of 'what it is like' to be one, or one's 'inner movie' - why should it matter whether one is aware of it or not? In many cases, of course, awareness of a pleasure can increase its value for one-say, by enhancing its quality in some way or by making it available as a source of interest or delight for one. But why think that without such awareness, the pleasure isn't good for one at all?

Feldman offers us only one reason to think this, his case of the subject whose life is filled with unconscious aromatic pleasures, but no others. It is implausible, he says, that this subject has a life high in well-being.

But it is possible that these pleasures add at least a little to this person's wellbeing, even if they do not make this person's life count as high in well-being. Why is such a person's life not high in well-being? Perhaps it is, not because these pleasures contribute nothing to well-being, but rather because these are the only pleasures this person experiences. The reason this person's life is not high in wellbeing is that it is missing all the other wonderful kinds of pleasures that are available to a normal adult human being.

Feldman might respond that if there were enough such unconscious aromatic pleasures, then, on my view, this subject's life would have to be high in well-being. But this isn't so. I am not committed to any kind of crude additive account, on which every pleasure adds to lifetime well-being. Indeed, in other work, I have argued that pleasures one experiences that are qualitatively identical to previous pleasures one has felt make no intrinsic contribution to one's lifetime well-being (though they might be instrumentally good for one in various ways). ${ }^{25}$

It is worth noting that the vast majority of contemporary philosophers of wellbeing have no trouble accepting that things might benefit one (non-instrumentally) even if one is unaware of them. Most desire-fulfilment theorists, for example, hold that what is good for one is getting what one wants, whether or not one finds out

\footnotetext{
${ }^{23}$ Feldman (2004, p. 73).

24 This, he thinks, might help a hedonist respond to the 'philosophy of swine' objection.

25 Bramble (2016).
} 
about it. ${ }^{26}$ Aim achievementists typically hold that what is good for one is achieving things whether one knows of these achievements or not. And so on. Why should it be different when it comes to pleasures and pains? My point here, to be clear, is not that we should defer to the opinion of the majority of philosophers, but merely that given the tide of philosophical opinion against him on this point, the burden seems to be on Feldman to explain why there is a difference when it comes to pleasures and pains.

\section{Conclusion}

In this paper, I have argued that neither Heathwood's nor Feldman's response to my objection to attitudinal theories succeeds. Both rely on a misunderstanding of the objection, since I did not claim, and do not hold, that the subjects in the Haybron and Sacks cases notice the cessation of a sensation. Moreover, Heathwood fails to consider the other evidence I have given for the claim that there can be pleasures and pains of which one is entirely unaware, as well as the expanded version of the objection mentioned above. Feldman, for his part, relies on the ill-defended and implausible claim that pleasures of which one is entirely unaware cannot be noninstrumentally good for one.

Open Access This article is distributed under the terms of the Creative Commons Attribution 4.0 International License (http://creativecommons.org/licenses/by/4.0/), which permits unrestricted use, distribution, and reproduction in any medium, provided you give appropriate credit to the original author(s) and the source, provide a link to the Creative Commons license, and indicate if changes were made.

\section{References}

Bramble, B. (2013). The distinctive feeling theory of pleasure. Philosophical Studies, 162, 201-217.

Bramble, B. (2015). The role of pleasure in well-being. In G. Fletcher (Ed.), The Routledge handbook of philosophy of well-being. London: Routledge.

Bramble, B. (2016). A new defense of hedonism about well-being. Düsseldorf: Ergo.

Carruthers, P. (2016). Higher-order theories of consciousness. In E. N. Zalta (Ed.), The Stanford encyclopedia of philosophy.

Feldman, F. (2004). Pleasure and the good life. Oxford: Clarendon Press.

Feldman, F. (2018). Unconscious pleasures and pains: A problem for attitudinal theories? Utilitas, 30, $472-482$.

Haybron, D. (2008). The pursuit of unhappiness: The elusive psychology of well-being. Oxford.

Heathwood, C. (2007). The reduction of sensory pleasure to desire. Philosophical Studies, 133, $23-44$.

Heathwood, C. (2017). Unconscious pleasures and attitudinal theories of pleasure. Utilitas, 30, $219-227$.

Rachels, S. (2004). Six theses about pleasure. Philosophical Perspectives, 18, 247-267.

Schwitzgebel, E. (2008). The unreliability of naive introspection. Philosophical Review, 117, $245-273$.

Publisher's Note Springer Nature remains neutral with regard to jurisdictional claims in published maps and institutional affiliations.

${ }^{26}$ Heathwood is a notable exception here. 